\title{
O arquivo pessoal de José Simeão Leal como fonte de informação e memória
}

Renata Lopes de Santanai

RESUMO:

Este artigo tem como objetivo verificar os diferentes exercícios de memória envidados por José Simeão Leal, através de suas anotações de campo, manuscritos e testemunhos na observância da cultura brasileira, em especial a paraibana. Neste sentido, este estudo foca o seu Arquivo Pessoal, dando visibilidade e (re)conhecimento ao titular, José Simeão Leal, bem como aos vários conjuntos e coleções documentais que o compõem. Para tanto, relatamos sua trajetória de vida pessoal e, concomitantemente, sua vida profissional como divulgador da cultura brasileira. Mais adiante, abordamos o contexto de formação dos Arquivos Pessoais e sua relevância como fonte de informação e memória. Por fim, de forma narrativa, descrevemos os artefatos informacionais, gêneros e tipos de documentos que compõem o Arquivo Pessoal de José Simeão Leal, patrimônio custodiado pela Universidade Federal da Paraíba (UFPB).

Palavras-chave: Arquivos Pessoais. José Simeão Leal. Memória. Informação.

\section{El archivo personal de José Simeão Leal como fuente de información y memoria}

\section{RESUMEN:}

La investigación objetivó verificar los diferentes ejercicios de memoria que realizó José Simeão Leal, a través de sus anotaciones de campo, manuscritos y testimonios en la observancia de la cultura brasileña, en especial la paraibana. En este sentido, este estudio se centra en su Archivo Personal, haciendo dar visibilidad y (re) conocimiento al titular José Simeão Leal así como a los diversos conjuntos y colecciones documentales que lo componen. Para ello, relatamos su trayectoria de vida personal concomitantemente a su vida profesional como diseminador de la cultura brasileña. Más adelante abordamos el contexto de formación de los Archivos Personales, y su relevancia como fuente de información y memoria. Por último, de forma narrativa, describimos los artefactos informativos, géneros y tipos de documentos que componen el Archivo Personal de José Simeão Leal, patrimonio custodiado por la Universidad Federal de Paraíba (UFPB).

Palabras clave: Archivos Personales. José Simeão Leal. Memoria. Información.

Data de submissão: 28/01/2018 - Data de aprovação: 03/06/2018

\footnotetext{
' Mestranda em Ciência da Informação pela Universidade Federal da Paraíba (UFPB); Especialista em Gestão Documental pela Universidade Federal do Rio Grande do Norte (UFRN); Graduada em Arquivologia pela Universidade Estadual da Paraíba (UEPB); Estudante do curso de Licenciatura em Letras Português pela Universidade Federal da Paraíba (UFPB)
} 


\section{INTRODUÇÃO}

A sociedade contemporânea assentada no principio da liquidez social busca de algum modo estabelecer diretrizes ou desenhar caminhos para a preservação da memória e a construção das identidades. Nesse sentido a Ciência da Informação avança nos estudos e pesquisas referentes às múltiplas fontes de informação inseridas nos Arquivos, Bibliotecas, Museus e Centros de Documentação, considerando a informação como artefato criado num tempo, espaço e com forma específica, suas principais características são a diversidade de suportes e seu contexto de produção.

Desse modo, considerando informação como artefato criado num tempo, espaço e com forma específica, suas principais características são: a diversidade de suportes e seu contexto de produção. Nessa perspectiva, a informação é percebida como um dos elementos fundamentais para a construção do conhecimento, de igual modo, a informação como artefato, só é estabelecida quando há uma relação de significado (SILVA, 1999).

Em vista disso, ao conhecermos os acervos que constituem os arquivos pessoais compreendemos que sua formação é resultante de um emaranhado de significados, do conjunto de atos do seu produtor, já que os documentos são reunidos de acordo com o modo de vida do sujeito, de seu tempo e do vínculo pessoal com o mundo, como observa Freire (2009, p. 46), nas palavras "Os arquivos privados pessoais revelam-se, portanto, como a própria consistência do sujeito, o lugar onde guarda aquilo que the é de foro íntimo, tendo nele um sentido pessoal, próprio". Por conseguinte, podemos observar que os arquivos pessoais são importantes "lugares de memória", pois são capazes de disseminar informações memorialísticas através do olhar do outro, constituindo-se como fonte de informação imprescindível para a compreensão da cultura popular brasileira.

Diante do exposto, esta pesquisa parte da necessidade de compreender o caráter informacional e memorialístico do Arquivo Privado Pessoal de José Simeão Leal, observando que seus registros feitos em diversos gêneros textuais da cultura popular brasileira, em especial a paraibana, bem como dos artefatos que compõem o acervo de Simeão Leal, disseminam as informações memorialísticas de nossa sociedade, contribuindo também como fonte de informação e memória para a Gestão Documental. Nessa linha de pensamento, temos como campo empírico o Arquivo Pessoal de José Simeão Leal, este se encontra no Núcleo de Documentação e 
Informação História Regional (NDIHR), localizado no Campus I da Universidade Federal da Paraíba (UFPB), órgão que está vinculado à Reitoria da Universidade.

Averiguamos no arquivo de José Simeão Leal documentos manuscritos e impressos sobre as mais diversificadas manifestações culturais paraibanas e que, por sua vez, apesar de ter passado anos e mais anos pesquisando, observando e anotando, não publicou nenhum registro dessas práticas culturais nordestinas. Ainda neste caminhar da pesquisa, continuei em minha graduação no curso de Arquivologia, na Universidade Estadual da Paraíba, tendo finalizado uma parte dos estudos em 2014, com o trabalho de conclusão de curso "Entre, rascunhos, anotações e escrituras: o arquivo privado pessoal de José Simeão Leal".

Com base nessas observações, percebemos a relevância desse acervo para a pesquisa, principalmente no campo da informação e da memória, pois contribui para descortinar o emaranhado de detalhes e signos presentes no acervo de José Simeão Leal, através de suas práticas pessoais e profissionais, compreendendo-as enquanto fonte de informação e memória. Para os pesquisadores e estudiosos, portanto, para todos os profissionais da informação, que de forma direta ou indireta atuam na Ciência da Informação, acreditamos que essa pesquisa vem dar sua contribuição, visto que os registros e relatos informais de José Simeão Leal e suas incursões na memória cultural são de interesse público, consequentemente colaborando na produção do conhecimento.

Tendo por base o panorama acima discutido, ao pensarmos nesta pesquisa deparamo-nos com situações multifacetadas, haja vista que estamos trabalhando com um Arquivo Privado Pessoal. Assim, ao adentrar em tal universo arquivístico, percebemos que os documentos que compõem os Arquivos Privados Pessoais possuem uma unicidade e singularidade em sua natureza e organização, pois não são provenientes de ações administrativas ou jurídicas (como encontradas nos Arquivos Institucionais), estes têm características e funções específicas. Sendo assim, é válido compreender que a formação de tais arquivos, é resultante do conjunto de atos do seu produtor, logo os documentos são reunidos de acordo com o modo de vida do sujeito, de seu tempo e do vínculo pessoal com o mundo, como sugeriu Oliveira (2009).

Consequentemente, os documentos pertinentes a esses arquivos representam as atividades sociais do seu produtor ou titular, como a vida familiar, civil, profissional, sua produção intelectual e artística, política, entre outros. Logo, a própria acumulação dos documentos pessoais é intencional, o titular guarda a memória que lhe é 
conveniente, que complementa sua vida e obra, conforme as observações de Freire (2009).

Para tanto, a situação estabelecida é a de que essa documentação acumulada por José Simeão Leal, segundo a pesquisadora Oliveira (2009) são artefatos informacionais que comprovam as suas perspectivas de observação das memórias sociais, ou seja, das vivências compartilhadas nas manifestações populares dos grupos culturais que ele visitou na Paraíba, cartas trocadas com amigos da literatura e da imprensa, e de seus objetos acumulados em vida. Esperamos que nosso trabalho contribua para a área da Ciência da Informação, mais precisamente na linha de pesquisa Informação, Memória e Sociedade.

\section{OS ARQUIVOS PRIVADOS PESSOAIS: ALGUMA CONSIDERAÇÕES}

A formação dos Arquivos Privados Pessoais e de Família tem seu início em meados do século XII, com o surgimento da arquivística grega. Nessa época, com o processo de conhecimento dos arquivos e de suas funções, originou-se a divisão dos documentos, ou seja, os arquivos foram divididos de duas formas fundamentais segundo suas atividades: públicos e privados. Em relação aos arquivos privados, Silva $(1999$, p. 66) sugere que:

\footnotetext{
O desenvolvimento do direito romano deverá ter contribuído para a proliferação de arquivos privados, que constituíam um instrumento essencial para o desenvolvimento dos negócios e garantia da propriedade dos cidadãos. Em Pompéia, no primeiro andar da casa do banqueiro Cecilius Jucundus, apareceu um grande cofre com a respectiva escrituração, feita em tabuinhas de cera. (SILVA, 1999, p. 66).
}

Nesses arquivos os documentos são resultantes das atividades estabelecidas por seu produtor, podendo a documentação assumir caráter público (quando relata as informações pertencentes à União, com conteúdos judiciais, estaduais e municipais) ou caráter privado (referente aos atos emanados por pessoas físicas e jurídicas de direito privado, podendo ser documentos empresariais, eclesiásticos, pessoais, de sindicatos, entre outros). Nessa perspectiva, é necessário um trecho da história da formação dos arquivos públicos e privados, ao dizer Gonçalves (1996, p. 6)

Será a partir do século XII, quando surgem os novos conceitos de - Estado, família e - Indivíduo, que se começam a construir os arquivos senhoriais, paralelamente aos arquivos reais, já sem o conceito de - arquivo público, mas sim com o de arquivo de indivíduos, de família a par dos arquivos eclesiásticos. (GONÇALVES, 1996, p. 6). 
Desta forma podemos compreender que a formação e definição de um arquivo pessoal e de família, confundem-se com as de arquivos privados, pois, dependendo das razões de produção (administrativas, profissionais, sociais, histórico-afetiva, pessoais) do documento, o mesmo é um bem cultural patrimonial de domínio público ou privado. Segundo registra Bellotto (2007, p. 207),

\begin{abstract}
A conceituação de arquivos pessoais está embutida na própria definição geral de arquivos privados, quando se afirma tratar-se de papéis produzidos recebidos por entidades ou pessoas físicas de direito privado (...). São papéis ligados à vida familiar, civil, profissional e à produção política e/ou intelectual, científica, artística, de estadistas, políticos, artistas, literários, cineastas, etc. Enfim, os papéis de qualquer cidadão que apresentem interesse para a pesquisa histórica, trazendo dados sobre a vida cotidiana social, religiosa, econômica, cultural, do tempo em que viveu ou sobre sua própria personalidade e comportamento. (BELLOTTO, 2007, p. 207).
\end{abstract}

Os arquivos pessoais e de família constituem uma fonte de informação relevante, estes adquirem o valor testemunhal e patrimonial, relativo às ações emanadas por seu produtor e sua relação com o mundo. O conjunto documental pessoal e familiar é organizado e selecionado segundo os critérios estabelecidos pelo próprio produtor, este de forma intencional passa a agrupar os documentos de acordo com os acontecimentos e necessidades que enaltecem sua trajetória de vida e de seus pares. Vale ressaltar que a acumulação de documentos pessoais, é válida para qualquer pessoa, não sendo apenas um privilégio para intelectuais do campo artístico e científico. Tal prática é lembrada por Artiercs, (1998, p. 11) que, em seu texto Arquivar a própria vida, assim esclarece:

\begin{abstract}
Arquivamos, portanto nossas vidas, primeiro, em resposta ao mandamento "arquivarás tua vida" - e o farás por meio de práticas múltiplas: manterás cuidadosamente e cotidianamente o teu diário, onde toda noite examinarás o teu dia; conservarás preciosamente alguns papéis colocando-os de lado numa pasta, numa gaveta, num cofre: esses papéis são a tua identidade; enfim, redigirás a tua autobiografia, passarás a tua vida a limpo, dirás a verdade. (ARTIERCS, 1998, p. 11).
\end{abstract}

Desta maneira, o procedimento de arquivamento pessoal e familiar tem como objetivo principal a socialização dos itens documentais que representam o vínculo pessoal do seu produtor, guardando as memórias de seu tempo e espaço, misturando a vida íntima e pública. Para Schellenberg (1974, p. 244),

[...] a maioria das coleções naturais de papéis privados sãos grupos orgânicos no sentido em que foram criados por uma entidade, igreja, um negócio, uma instituição erudita ou coisa parecida, ou por pessoa ou família dedicada a uma determinada atividade. Uma grande coleção de papéis privados produzidos por um indivíduo tem, também, algumas características de um grupo de arquivos, 
pois o indivíduo que cria uma grande coleção deve executar muitas atividades para criar muitos papéis, e essas atividades, provavelmente, são a base pela qual seus papéis são agrupados e organizados durante a sua vida. (SCHELLENBERG, 1974, p. 244).

Os documentos pessoais e de família levam seu produtor ou titular a uma constante triagem na guarda de suas informações, por receio de leituras equivocadas ou pela publicação de conteúdos íntimos, envolvendo a si próprio ou a terceiros. Assim, tais documentos que compõem os Arquivos Pessoais e de Família, obtém o sentido monumental/histórico, pois servem como fonte de pesquisa para a história e o desenvolvimento científico e, posteriormente, servindo para o âmbito de divulgação. Desse modo, segundo Bellotto (2006, p. 265) a caracterização de arquivo pessoal e de família é

[...] constituído por documentos produzidos e/ou recebidos por uma pessoa física (cidadão, profissional, membro de família ou elemento integrante de uma sociedade), enfim, de documentos que, preservados para além da vida dessa pessoa, constituem seu testemunho, como conjunto orgânico, podendo então ser aberto à pesquisa pública. (BELLOTTO, 2006, p. 265).

Desta forma, os documentos pessoais deixam de ser completamente privados, passando de acordo com suas atividades e funções, a terem uma qualidade orgânica de documentos possuidores de interesse público e social. Vejamos o que diz Camargo (1998, p.6),

[...] a interpretação progressiva do público e do privado, dissolvendo sua relação originária, têm múltiplas facetas. Não só os interesses privados passaram a ter importância pública, o que pode ser observado pela crescente intervenção do Estado no setor privado - sobretudo no seu direito de dispor livremente da propriedade - como também houve transferência de competências públicas a entidades privadas. A esse fenômeno, que Habermas caracterizou como de socialização do Estado e de estatização da sociedade, corresponde o de - publicização do direito privado e privatização do direito público. (CAMARGO, 1998, p. 6).

Assim, no que se refere aos arquivos pessoais e de família, devemos compreender que a organicidade é o elemento que difere no acumulo, na seleção e organização dos documentos, e também no entendimento de seu valor histórico e cultural. Mais adiante, para complementar os estudos a respeito dos Arquivos Privados Pessoais (de Família, Grupos e de Indivíduos). O arquivista Cook (1998), questiona os princípios e conceitos tradicionais da Arquivologia, no campo dos Arquivos Institucionais e Arquivos Pessoais. Assim, Cook considera que a partir do século XX é necessário que haja uma atualização do fazer arquivístico, particularmente na avaliação e descrição dos documentos, visando sua inclusão em instituições de arquivos. Para 
tanto, este autor, com sua experiência mostra como os arquivistas dos Estados Unidos e da Austrália lidaram com os arquivos públicos e pessoais:

Entre esses dois tipos de arquivos, o público e o pessoal, o oficial e o individual, existe em muitos países uma divisão incômoda, ou mesmo uma tensão. Em grande parte da literatura arquivística dos Estados Unidos, por exemplo, há referências a duas partes distintas da profissão: a tradição dos manuscritos históricos versus a tradição dos arquivos públicos. Na Austrália, é revelador o titulo do periódico nacional dos arquivistas: Archives and Manuscripts, que ressalta a nítida dualidade que lá encontrei, com alguns arquivistas de arquivos públicos na verdade ignorando seus colegas que coletam manuscritos, não os considerando arquivistas, e sim profissionais mais próximos, em seu trabalho e em sua visão dos documentos, dos bibliotecários ou dos curadores de museus. (COOK, 1998, p. 130).

Sendo assim, muitos arquivistas não consideravam (ou não viam) a relevante necessidade de coletar e, posteriormente, fornecer o uso e acesso dos manuscritos individuais de família e grupos. Nessas conjunturas interpretativas, a Europa continua sem recolher os manuscritos pessoais, conforme assinala Cook (1998, p. 130):

Em boa parte da Europa e em muitas de suas antigas colônias, os arquivos nacionais, via de regra, não recolhem papéis pessoais de indivíduos particulares (exceto de políticos e burocratas) em bases iguais as dos documentos oficiais do governo nacional. Esse padrão se repete nos níveis dos governos e arquivos estaduais, provinciais, regionais e locais ou municipais. Quanto ao destino dos arquivos pessoais ou dos manuscritos privados, na maioria dos países são adquiridos pela biblioteca nacional, pelas bibliotecas regionais, ou pelas principais universidades e, até mesmo, por museus e por institutos de pesquisa ou documentação temáticos ou especializados. Assim é que os diversos domicílios institucionais dos arquivos públicos e pessoais reforçam suas diferenças, tanto quanto o fazem suas distintas origens e estruturas legislativas. (COOK, 1998, p. 130).

Desta forma, podemos aferir que entre estes tipos de arquivo (público e pessoal) ambos devem ter o mesmo papel ativo para os arquivistas e suas instituições representantes. Nessa abordagem, é interessante conhecermos que existem as semelhanças ou conformidades técnicas, entre os documentos institucionais públicos e privados. Para Cook (1998, p. 131), as particularidades são:

Primeiro, ambos são artefatos de registro derivados de uma atividade; os arquivos são evidências das transações da vida humana, seja ela organizacional e, por conseguinte, oficial, seja individual e, portanto, pessoal. Diversamente de livros, programas de televisão ou obras de arte, eles não são intencionalmente criados por motivos próprios, com a possível exceção dos textos autobiográficos, mas surgem, antes, dentro de um contexto, como parte de alguma outra atividade ou necessidade, seja pessoal, seja institucional. Em segundo lugar, os arquivistas, tanto nos arquivos públicos quanto nos pessoais, frequentemente usam procedimentos técnicos e métodos práticos semelhantes, em termos de como acessam, descrevem, armazenam fisicamente e conservam os arquivos e os colocam à disposição para fins de pesquisa. (COOK, 1998, p. 131). 
Ainda assim, apesar de todos os esforços do pesquisador Terry Cook em seu documento-proposta do Seminário Internacional sobre Arquivos Pessoais, é visível certo engessamento nos conceitos e princípios arquivísticos (e, consequentemente, de alguns arquivistas e de muitos discípulos teóricos) quanto à forma de acumulação de documentos institucionais e oficiais em arquivos, como tece o estudioso:

\begin{abstract}
O documento do Seminário afirma também que os arquivos públicos, ou institucionais, ou oficiais, são acumulações "naturais e necessárias", subprodutos orgânicos da atividade administrativa, enquanto os arquivos pessoais, conquanto possam ter tal qualidade, frequentemente são - de novo nas palavras do documento do Seminário - "produtos de um desejo de perpetuar intencionalmente uma certa imagem", um "(propósito) concebido que, na verdade, se destina à 'monumentalização' do próprio indivíduo ... ". (COOK, 1998, p. 131).
\end{abstract}

Diante do exposto, é latente a propagação da estrutura conceitual entre arquivos públicos e arquivos pessoais (principalmente em países que têm o inglês como primeira língua), de modo que, a diferença é que o primeiro é produzido com um objetivo - natural-orgânico no decorrer das atividades administrativas nas instituições, já os documentos de indivíduos, grupos ou de família são gerados de acordo com a intenção de seu produtor e de acordo com o contexto sócio-histórico-cultural ao qual está inserido.

\title{
3 JOSÉ SIMEÃO LEAL: FAZERES E VIVERES
}

José Simeão Leal, paraibano da cidade de Areia, nasceu em 13 de novembro de 1908. Este areiense destaca-se pela verdadeira representação da identidade histórico cultural de nosso país, principalmente devido a sua forte atuação na circulação, produção e divulgação de jornais, revistas e livros, dando início no Brasil ao universo editorial no campo público bem como fornecendo a visibilidade das obras de artistas e escritores do nosso país.

A despeito disso, têm sua formação acadêmica em Medicina (Universidade do Rio de Janeiro, 1936), mas a história, cultura e as artes sempre foram suas paixões, sendo assim, atuou como jornalista, colecionador, médico, escultor, administrador cultural, crítico de arte (ABCA/AICA), secretário de Estado na Paraíba, membro fundador da Associação Brasileira de Crítico de Arte, diplomata e 1ำ editor público do Brasil. Desta forma, tornou-se um dos principais integrantes pela preservação e difusão do patrimônio artístico cultural brasileiro, que revelava talentos literários e conquistava 
amizades como: Flávio de Aquino, Clarice Lispector, Manuel Bandeira, Rachel de Queiroz, Sergio Milliet, entre tantos outros intelectuais.

José Simeão Leal é portador de um currículo diversificado tendo atuado como jornalista, crítico de arte, diplomata, adido cultural, na qual seu trabalho de maior relevância foi como diretor do Serviço de Documentação do Ministério da Educação (MEC), período (quase 19 anos) de grande produção, circulação e divulgação do pesquisador, este que por sua vez, mostrava-se interessado na cultura popular, na (re)qualificação dos valores das manifestações culturais (cantigas de roda, congos, danças africanas, adivinhações, nau catarineta, vaquejadas) realizando diários de campo, coleta de dados e observações informais de suas viagens em nossas cinco regiões brasileiras.

José Simeão Leal contribui como fonte de informação, pois por toda sua vida, proporcionou o conhecimento, a sociabilidade e a proteção do patrimônio cultural brasileiro. É válido ressaltar que mesmo vivendo um bom tempo no Rio de Janeiro, José Simeão Leal nunca deixou de apreciar sua terra natal, inclusive seu maior sonho era que a Paraíba tivesse uma biblioteca igual ou melhor que a sua, como prova dessa nostalgia por seu povo, da saudade da sua terra tão amada, dos parentes e amigos, após sua morte em 02 de julho de 1996, em respeito ao seu desejo e pedido, para sua esposa, a viúva D. Eloah Drummond, o acervo de José Simeão Leal foi transferido para a Paraíba.

Percebemos que o acervo de José Simeão Leal está dotado de expressões populares, de interação particular com seus amigos, de suas atividades com os artistas Carlos Drummond de Andrade, Celso Cunha, Caribé, Tomás Santa Rosa Júnior e com sua esposa Eloah Drummond. Ainda sob esta ótica, na próxima seção iremos descrever a documentação que compõe o acervo de José Simeão Leal'1.

\footnotetext{
1 "No cerne de sua trajetória de vida, inscreveu-se o mundo, fragmentado, desconexo, ao mesmo tempo organizado, com base em um critério rigoroso, bem articulado aos valores que o presidiram. Em rápida passagem pelo percurso de vida, registra-se um Simeão médico, professor, secretário de Estado na Paraíba, adido cultural, representante brasileiro em vários países, jornalista, editor, amante e pesquisador da cultura popular, membro fundador da Associação Brasileira de Críticos de Arte, diretor da Escola de Comunicação e Artes, membro fundador da Escola Superior de Desenho Industrial, ambas no Rio de Janeiro, membro da comissão organizadora da I e da II Bienal Internacional de São Paulo. Nesta última, atuou como curador da exposição que homenageou Eliseu Visconti, por considerá-lo "o verdadeiro marco da pintura moderna no Brasil", sem menosprezar o trabalho de excepcional importância realizado por Anita Malfatti, Tarsila do Amaral, Lasar Segall, Di Cavalcanti e outros, pioneiros do Modernismo no Brasil." OLIVEIRA, B. M. J. F. Memória e Arquivos Literários: a escrita de si mesmo como registro intimista. In: Anais do XI Encontro Nacional de Pesquisa em Ciência da Informação, 2010.
} 


\section{CONHECENDO O ACERVO DE JOSÉ SIMEÃO LEAL}

Atualmente, o Arquivo Pessoal, na categoria de Arquivo Literário, de José Simeão Leal encontra-se no Núcleo de Documentação e Informação História Regional (NDIHR), localizado no Campus I da Universidade Federal da Paraíba (UFPB), que têm entre seus principais objetivos o resgate e a preservação da memória brasileira e a produção do conhecimento crítico sobre a realidade nordestina. $O$ acervo tem como

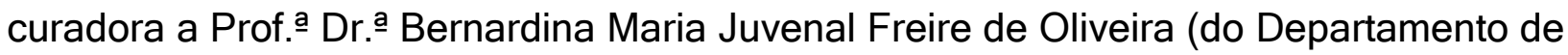
Ciências Da Informação/UFPB), sendo a arquivista Laudereida Eliane Marques Morais responsável pelo acervo. Para tanto, o acervo pessoal de Simeão é composto por recortes de jornais, pinturas, fotografias, correspondências, periódicos, livros, manuscritos inéditos de pesquisa, esculturas e objetos pessoais, estes documentos têm acesso livre para usuários (obviamente alguns documentos não, por serem de cunho privado, que envolvem outras personalidades, como ocorre no caso de algumas cartas), sendo o arquivo aberto à pesquisa, basta entrar em contato com a arquivista responsável pelo acervo, Laudereida Marques Morais, mencionada anteriormente. Vale ressaltar, que nunca foi feito um inventário do acervo, mas que existe o catálogo, servindo como instrumento de pesquisa, descrevendo as tipologias documentais e seu estado de conservação. Também não podemos deixar de mencionar que alunos e professores se empenham em pesquisar e divulgar a biografia de José Simeão Leal e de seu acervo, elaborando teses, dissertações e trabalhos de conclusão de curso. Neste sentido, o acervo de José Simeão Leal é composto por 2007 cartas, 5400 livros, 532 quadros, 7 gravatas, 3 cachimbos, 3 relógios. Segue abaixo o quadro síntese das tipologias documentais do acervo:

QUADRO 1 - Demonstrativo das tipologias documentais

\begin{tabular}{|c|c|}
\hline Tipo Documental & Quantidade \\
\hline Livros & 5.400 (titulos que formavam a biblioteca pessoal) \\
\hline Pinturas & 537 (todas de sua própria autoria) \\
\hline Cartas recebidas e expedidas & 2.007 (manuscritas e datilografadas em papel) \\
\hline Esculturas & 05 (em ferro) \\
\hline Objetos pessoais & $\begin{array}{c}\text { Gravatas em seda, cachimbos, comendas, } \\
\text { medalhas, abotoadura e broches para gravatas, } \\
\text { relógios etc. }\end{array}$ \\
\hline
\end{tabular}

Fonte: Oliveira; Córdula; Andrade, 2011.

5 CONSIDERAÇÕES FINAIS 
Ao longo deste trabalho, percorremos a trajetória de vida pessoal e profissional de José Simeão Leal, este que, por sua vez, ao buscar, coletar, descrever, produzir, circular e editar as práticas sociais e simbólicas da cultura brasileira, nos deixa um legado histórico sobre nossos ancestrais, nossas histórias, cotidiano e costumes. O pesquisador, por meio de sua atuação como jornalista, editor e crítico de arte (além de tantas outras áreas que se dedicou), nos revela a sua forma intencional de querer manter vivas as memórias individuais e coletivas da sociedade. Seus escritos são importantes fontes de informação, pois recontam o passado do cenário artístico-cultural do Brasil modernista.

Nesse movimento, configura-se uma relação de continuidade da cultura, de circularidade em um tempo-espaço marcado pelas investigações de um coletor de peças, objetos, artes, pessoais e escritos, que procurava de maneira sutil, identificar, as identidades: nacional, local e regional, como por exemplo, na Paraíba, sua terra natal, as seguintes manifestações: Nau Catarineta, os Congos, a Lapinha, as danças e religiões de matiz africanas, as adivinhações, as Cantigas de roda, entre outras diversas tradições populares.

Ainda sob este contexto, podemos averiguar a relação de proximidade a qual o referido pesquisador sempre teve com sua terra, vindo todos os anos, em suas férias, recolher, anotar e buscar os vestígios e tradições de uma cultura da comunidade social na Paraíba e, antes de falecer, pediu a sua esposa que seu acervo ficasse na Paraíba, terra que tanto amou e que divulgou sua história e cultura. Sendo assim, é por meio desses fragmentos e marcas do passado que podemos compreender um pouco mais do fazer-registrar-salvar de Jose Simeão Leal. Isso o torna importante para não cairmos nos abismos dos esquecimentos, principalmente, para a sociedade brasileira, confirmando a necessidade de preservar e dar visibilidade de seu acervo para a memória nacional.

Percebemos o quanto se faz necessário trazer para o cenário acadêmico os vestígios, relíquias e testemunhos situados no conjunto documental de José Simeão Leal, tais manuscritos e demais artefatos informacionais, são resultado dos diferentes exercícios de memórias, do ato de recolher marcas, fragmentos e sinais, nos auxiliam a (re)conhecer e refletir sobre tais práticas culturais brasileiras e suas variantes sociais e culturais.

Em razão disso, estamos convencidos a respeito da notoriedade que José Simeão Leal dá à cultura, entendida sob uma perspectiva de transformação processual 
e de (re)encontro com a matriz identitária. Essa é uma forma de possibilitar novos diálogos na formação de saberes e conhecimentos, no campo da Arquivologia, História, Biblioteconomia, Museologia e da Ciência da Informação, fomentando novas perspectivas multidisciplinares, por meio do Arquivo Privado Pessoal de José Simeão Leal, mediante a diversidade de objetos, relatos informais, observações e, principalmente, de seu olhar etnológico no tocante à memória de nosso país. Assim, somos capazes de (re)significar concepções de cultura, memória e história.

\section{REFERÊNCIAS}

ARTIERCS, Philippc. Arquivar a própria vida. Estudos Históricos. Rio de Janeiro: CPDOC/FVG, 1998.

BELLOTTO, Heloísa Liberalli. Arquivos permanentes: tratamento documental. 5. ed. Rio de Janeiro: FGV, 2007.

2006.

Arquivos permanentes: tratamento documental. 4. ed. Rio de Janeiro: FGV,

CAMARGO, Ana Maria de Almeida. Contribuição para uma abordagem diplomática dos arquivos pessoais. E-mail para Zeny Duarte. 18 maio 1998.

COOK, Terry. Arquivos pessoais e arquivos institucionais: para um entendimento arquivístico comum da formação da memória em um mundo pós-moderno. Estudos Históricos, Rio de Janeiro, v. 11, n. 21, 1998.

GONÇALVES, Manuel Silva; GUIMARÃES, Paulo Henrique; PEIXOTO, Pedro Abreu. Arquivos de família: organização e descrição. Vila Real: Universidade de Trá-os-Montes e Alto Douro, 1996. 55p.

OLIVEIRA, B. M. J. F. de. José Simeão Leal: escritos de uma trajetória. Tese (Doutorado em Letras). Universidade Federal da Paraíba, João Pessoa, 2009.

OLIVEIRA, B. M. J. F., CÓRDULA, A. C. C., ANDRADE, B. A. DIREITO À MEMÓRIA: processo de tombamento do acervo José Simeão Leal. In: Revista brasileira de arqueometria, restauração e conservação. v.3, p.1 - 6, 2011

SCHELLENBERG, T.R. Arquivos modernos: princípios e técnicas. Tradução NilzaTeixeira Soares. Rio de Janeiro: Fundação Getúlio Vargas, 1974. 345p.

SILVA, Armando B. Malheiro et al. Arquivística: teoria e prática de uma ciência da informação. Porto: Afrontamento, 1999. 254p. (Biblioteca das Ciências do Homem, Série Plural, 2). 